\title{
FORUM
}

\section{Mathematics and the Collision Regulations}

\author{
from Captain F. J. Wylie, R.N.
}

RECENT articles in this Journal will have suggested that there is a conflict between certain mathematicians and certain mariners on the subject of the efficacy of the Collision Regulations. The controversy is really philosophic rather than mathematical and, although it would never be suggested that the mathematical system we have seen is anything but flawless in isolation, there are grave doubts that it would work, even on a planet composed solely of deep water and supporting ships staffed only with mathematicians, having collision avoidance as their single preoccupation.

The issue is between a system which specifies unequivocally the kind of action permitted and one which depends upon allocating responsibility for keeping clear coupled with a few manœurring DoN'Ts.

It must be assumed that the former system would be drawn up in the form of rules which would in some way compel obedience. It would be necessary to decide whether the manœuvres would be compulsory for one or both ships and, if one, which one. For such rules to be effective ships would need to be assured that all other ships in the vicinity would be aware of their own commitments and would meet them. It will be obvious that awareness cannot be assumed except in clear weather. A ship will also want to be assured that, in following the rule, her contribution to safety will be positive in all the circumstances in which it can be applied. This will not be so if a manœuvre to avoid one 'threat' is not that to be expected by a ship constituting another which exists concurrently. The required manœuvre must, of course, be practicable from the point of avoiding navigational hazards other than ships.

Rules based on manœuvring directive would have to embody even more precisely a definition of the circumstances in which a particular ship becomes bound to commence action vis-à-vis another particular ship. If this is not done, a mancuvre such as an alteration of course towards the destination, a precautionary reduction of speed on entering reduced visibility or a 'system' alteration in respect of a third party may be misinterpreted. The necessity for this becomes more acute as the number of ships in the area increases.

If only responsibility is defined, the activating phrase 'when there is risk of collision' is satisfactory but, when specific action is demanded, it represents too long and too vague a period of time; it is this probable ambiguity which would vitiate any system based solely on mathematics. The tendency of purveyors of panaceas is to base their theories on two-ship situations. In the maritime field this over-simplification represents one of the main differences between theory and practice. Whatever may be the case in the air, it is unusual at sea for a ship to be able to take action without having regard to its effect on others than the one she is immediately trying to avoid. Account has to be taken of this because 
any definition of the moment for action is liable to be rendered nugatory by the quite usual approach of other ships from different directions and ranges and at various speeds.

Further, if the term 'when there is risk of collision' is used to define the circumstances which demand action, it will be noted that, in the maritime case, a definition, satisfactory in the clear weather case (a steady or nearly steady bearing), would be wholly inadequate when the circumstances include poor visibility. In clear weather, if ships are shaping to pass clear or if action is being taken in accordance with the rules to make them do so, a close passing other than ahead is not an occasion for apprehension. In fog, with or without radar in use, and particularly in congested waters, the situation is vastly different and it is fairly generally agreed that approaches of less than 2 or 3 miles should be avoided if possible and, if they cannot be, speeds should be greatly reduced.

The mathematicians seem to claim it as a virtue of their systems that the action required depends on no circumstances other than the relative bearing; questions of range, speed of approach and visibility are considered quite irrelevant. This factor alone would seem to make the mathematical approach unacceptable for maritime purposes.

The Rule of the Road has many good points even if it does not include that of being completely foolproof. Its great virtue is that it defines responsibility rather than action but it does warn against manouvring to pass ahead and now states a preference (when using radar) for the starboard turn. The virtues present in these qualifications include that of commonsense and, one might say, politeness.

In clear weather Crossing cases, Rules 19 and 22 make it usual for the giving way ship to pass under the stern of the other. When the bearing has been steady it can do this by reducing speed or by a turn to starboard. In the Overtaking cases the habit of passing under the stern is equally effective and courteous. The possible ambiguity which confronts the ship approaching from about 2 points abaft the starboard beam in daytime (at night there would be no ambiguity) is resolved by placing the responsibility on that ship, which should surely be able to resolve the dilemma while still some distance off.

In both Crossing and Overtaking contexts, cases occur in which the give way ship passes ahead at distances which make the manœuvre perfectly safe. This is a question of judgment in discharging the responsibility allocated by the Rules.

The 'head on' or nearly 'head on' approach in clear weather, with the Rule for the port to port passing should really present no difficulty.

Vast numbers of seamen learn the Rules in their youth without difficulty and follow them through their lives without mishap. The mathematicians evidently feel that the existence of separate rules for the ahead, crossing and overtaking situations together with the injunction against mancuvring to pass ahead and that which releases the stand-on vessel from her obligations when catastrophe is imminent, makes the whole affair nonsensical and too complicated for the seaman. They will find many who, while appreciating their desire to help, disagree with them strongly.

\section{H. Sadler (Superintendent, H.M. Nautical Almanac Office) comments:}

There may well be misunderstanding between navigators and those to whom Captain Wylie refers as mathematicians, but I hope and believe that there is no conflict. In any complicated problem, particularly one involving human qualities 
of judgment, decision and action, there are aspects that are capable of complete analysis and others which must be regarded as imponderables. No one is foolish enough to suggest that the solution of such problems can be based solely on the study of those factors which can be analysed, but equally no one can deny that it would be unwise to ignore the results of the complete analysis of all such factors. The mathematics of collisions, although basically simple, lead to some surprisingly complicated geometry and to some rather unexpected results. It is the mathematician's job (which he may inadequately fulfil) to express the results of this analysis in relatively simple form; all he asks is that these results, which are the incontrovertible consequences of the stated set of circumstances, should be taken into consideration when framing rules and regulations. They must be weighed with all the other factors involved; but unlike the other factors, which have a large range of uncertainty, those arising from the mathematics are specific and definite. It may well be that the range of uncertainty in the imponderables is so great that the results of the mathematical analysis contribute little that is positive to the final solution; but they impose definite limitations, and it is not clear that these are yet fully understood or incorporated.

I am certain that in none of the so-called mathematical papers published in the Journal have the authors intended to do more than make a contribution to a small portion of the whole problem. In my view, however, no consideration of the anti-collision problem can be regarded as complete without a full understanding of the consequences of the mathematics; there still remains much to be done and every progressive paper is to be welcomed as a contribution to that full understanding.

\section{Rear-Admiral J. A. Gauw, R.Neth.N.(ret.) comments:}

With regard to mathematics, it is my opinion that a captain with practical knowledge of relative motion and the influence of the speed-vectors of two ships on their speed of approach and relative bearing, has a great advantage over those without such knowledge when it comes to taking the right decision to avoid collision at the right time.

However, we must face the fact that a good many of those who are responsible for the safe navigation of ships lack the required mathematical background. We therefore need regulations that are easy and safe for all to work with. When danger of collision between two ships arises, it ought to be clearly stated which ship should pass ahead and which astern. Safety would be greatly furthered if both ships would manœuvre in coordination. We should therefore abolish all the existing Rules which give one of the ships the passive duty to stand-on until the time has come for an escape mancuvre which so often has resulted in misunderstanding and disaster. Safety would also be furthered if the same Rules were to apply to ships in visual sight and ships in radar-contact. This could be achieved if ships of all kinds were required to follow the same Rules and compelled to take the same avoiding action, no matter whether engine-propelled, sailing, towing or trawling. The only ships to be exempted from taking avoiding action should be those that are unable to do so for any reason.

The virtue of the existing Rules may be to make it easier to define responsibility, in most cases pinning it automatically on the ship that is to give way. The defect, as I see it, is that action should prevail and that one ship acting alone can never achieve as much as coordinated action as both. Of course the action of both 
ships in avoiding collision must be taken with due regard to other ships in the vicinity and to other possible navigational dangers. In view of these additional circumstances no predetermined mathematical or other too-rigid system would ever work. The Rules should state exactly how ships are to pass clear of each other, leaving to the discretion of their masters when to start the manœuvre and how to carry it out.

There are only three different ways in which two ships can approach to a point of collision, therefore three different Rules are necessary. I submit these in an abbreviated form:

(1) Head-on approach of two ships on opposite courses (or nearly so): Both to mancuvre so as to pass port to port.

(2) A ship approaching another from dead-astern on the same course (or nearly so): Both to manœuvre so as to overtake and be overtaken on the starboard side.

(3) Course-crossing ships: The one having the other ship to starboard to mancuvre so as to pass astern; the one having the other ship to port to mancuvre so as to pass ahead.

(4) A ship unable to comply with Rules 1, 2 and 3 must keep her course and speed.

(5) If a ship acting under Rule 4 stands-on, the other ship manauvring according to Rules 1,2 or 3 has to avoid the collision.

Note: Rule 4 provides for ships unable to manœuvre and for a ship having no radar.

It is a mere coincidence that the sight-line of the ships involved will turn anti-clockwise in all cases when manœuvres are carried out in accordance with Rules 1, 2 and 3.

The above-mentioned Rules were proposed in the Forum of this Journal as long ago as $1955(8,178)$.

Finally, let us consider the question of eventually reversing these Rules. I oppose reversing the Rules even when good communication between both ships is assured. During my long career at sea I have witnessed too many collisions caused by misunderstanding and disagreement when ships were trying to reverse existing Rule 18. Many will recognize the picture: two ships approaching head-on, one giving repeatedly two blasts while the other one does not agree and keeps giving one blast, both ending with three blasts and collision which could have been avoided by keeping to the existing Rule. The French adage: ordre, contr'ordre, désordre, should be kept out of the Regulations. I therefore recommend, no reversal of the Rules, but let us keep the sight-line turning anti-clockwise.

\section{Commander P. Clissold, R.N.R. comments:}

Captain Wylie points out the natural doubt of the practitioner that the theorist can solve his problems. In avoiding collision in fog at sea the situation, as he says, is often complicated by the presence of other vessels and navigational hazards, which can produce such a variety of circumstances that no rule of manœuvre can be expected to cover them all.

The position to which years of discussion and thought about this problem have led is summed up in the Ministry of Transport Notice No. M 4 I 5 (December 
1960) which was issued after the International Conference on Safety of Life at Sea. It states that radar does not relieve a vessel from the obligation of conforming strictly with the Rules (which are clearly thought to be satisfactory-so far as they go); adds that Rules 17 to 24 apply only to vessels when one can be observed visually from the other; and concludes with sound advice about manœuvring generally and a guarded reference about altering course to starboard which 'is generally preferable to an alteration of course to port'.

The navigator is thus left with freedom of action, but little specific guidance, during the time between observing an echo and sighting the ship which returns it. It is here, surely, that the theorist can help; not in providing a strict Rule, but a plan of manouvre which should usually be followed, circumstances permitting. If it is possible to provide such a guide it would be of immense benefit to the navigator, for he not only would know what he will be expected to do, but he will know what the other ship will probably do. (He cannot know for certain, for he cannot tell if the other is using radar or not, though it is becoming increasingly likely that both will be.)

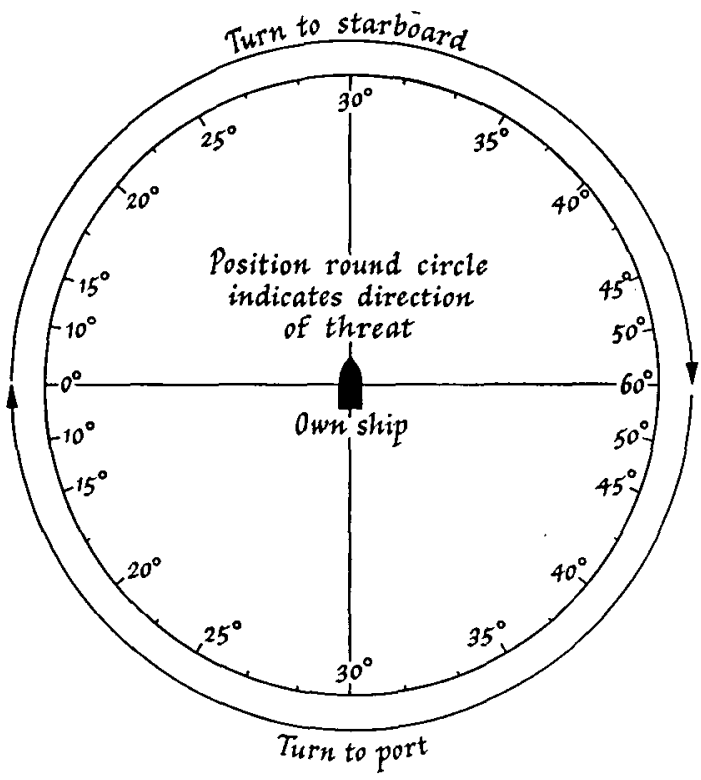

FIG. I. Dr. Hollingdale's turning rules (slightly simplified) to produce a miss distance of at least half the range at which course is altered(if both ships manœuvre).
It seems to me that Dr. Hollingdale has provided such a guide to action, 4 which is simple, precise, and (I imagine) mathematically impeccable. Dr. Calvert's latest paper $^{2}$ appears to support this view.

Fig. I, slightly modified from Dr. Hollingdale's figure, shows the approximate alteration of course necessary to obtain a miss distance of half the observed range if both vessels alter.

This system of collision avoidance could be subjected to tests upon a simulator, similar situations involving more than two ships in open water being dealt with first, preferably, by students who had no knowledge of the Hollingdale plan, and then
ense. If comparison of the by the application of his rules plus commonsense. If comparison of the
results obtained was sufficiently favourable, the attention of members of the International Conference on Safety of Life at Sea could be drawn to them and recommendations made in the same way as in Notice No. M 415.

Captain C. J. Wynne-Edwards, D.S.C., R.N. writes:

The mathematics of avoidance of collision between two ships in open water is extremely simple, and one does not need to be a senior wrangler to understand 
it. It is, in fact, much more fully appreciated by the practical seaman than the mathematicians appear to think. It is an easy matter to devise a set of rules which, if meticulously followed, will ensure that two ships approaching each other will not come into collision. It is not so easy to ensure that the same rules will apply equally effectively in narrow waters when not two, but perhaps half a dozen ships are potentially involved, half a dozen more are in the offing, and each one of these is being controlled by a human being subject to human fallibility.

Those wise seamen who devised the present Collision Regulations were doubtless fully aware of the mathematics of relative motion, but they also appreciated the many uncertainties and the infinite variety of conditions which obtain at sea, and knew full well that human judgment and a broad philosophy must play their part in helping to solve the collision problem. There is an old doggerel which is used (or used to be) to help the very young to remember some of the first principles:

$$
\begin{aligned}
& \text { If on your starboard red appear } \\
& \text { It is your duty to keep clear: } \\
& \text { To act as judgment. says is proper; } \\
& \text { Port or starboard, back or stop her. }
\end{aligned}
$$

In the present context the important points in this little rhyme are that under certain conditions, (a) The Officer of the Watch has a duty to keep clear: not a duty to alter course $x$ degrees this way or that if the bearing does not change, but to take avoiding action within a prescribed code, and $(b)$ that he must use his judgment of the precise conditions obtaining to govern such action.

Captain Wylie has, in the foregoing article, put the whole case admirably, and his opening paragraph is a masterpiece. The nub of the matter is, however, really contained in his assertion that the success of any set of unequivocal rules must depend upon invariable obedience to them. Such obedience cannot, of course, be guaranteed and there are a hundred reasons why, on occasion, the rule will be broken or ignored. It has been argued that the danger of collision would be lessened if avoiding action, when necessary, was incumbent upon both the ships involved. One argument in favour of rules based on such a hypothesis is that if both ships have to take positive action the miss distance will be increased, whereas if only one carries out her obligations a collision will still be avoided. The Regulations might have been formed on such a basis, and I have no doubt that serious consideration was given to it. In the event it was decided, I think wisely, that the onus should, under all except one set of conditions, devolve upon only one ship. The overwhelming argument in favour of this decision is that only on this premise can the precise actions of one of the two ships be forecast by the other with confidence and certainty; and, as a bonus to that argument, the right of way vessel can proceed without deviation towards her destination.

I think that in discussions about the merits and shortcomings of the Regulations too much notice is perhaps taken of the collisions which do occur, and far too little of those which do not. Captain Wylie quite rightly makes the point that 'vast numbers of seamen learn the Rules in their youth without difficulty and follow them through their lives without mishap'. The fact is that the present Regulations are enormously successful in achieving what they set out to achievethe prevention of collision at sea. Most seamen are convinced that their blend of philosophy, definition of responsibility, and peremptory insistence on certain essentials is about the best which can be devised. 
Capt. di Fregata M. Bini, Italian Navy, writes:

I quite share Captain Wylie's ideas, that there is a big difference between theory and practice and if it is quite true that the mathematical investigation of the collision problem can provide the seaman with a useful background of knowledge, it is equally true that it would hardly have any practical use and that only good sense, the Rules of the Road, radar plotting and politeness can cope with the infinite variety of cases that may happen at sea. Let us see how they work out in practice:

(a) Good sense. A Fairplay number of last spring tells of a collision in which one of the ships had its radar set on the I-mile scale. It is evident that nothing can be of any use when good sense is lacking.

(b) Rules of the Road. As with everything made by man they are not perfect, but at least the existing ones besides being known world-wide have also undergone years and years of use and have from time to time been improved as far as possible. Why then start the whole thing again?

(c) Radar plotting. Being accustomed to sail in naval units where radar plotting is continuously maintained on the tactical table, I probably see the problem from a different angle because radar plotting gives reliable and timely information on other ships' course, speed and distance of closest approach and so enables one to take action long before the situation becomes dangerous. On the other hand, the plotting shows clearly that the greatest majority of ships have a definite tendency to take action with considerable delay, and one almost has the impression that altering course is for them a most uncommon event.

(d) Politeness. I most heartily agree with Captain Wylie on this point, not only because at sea nowadays one generally feels that, it is being forgotten more and more, but also because politeness-which often means more properly 'intelligence'-is sometimes the only solution to complex problems that arise when more than two ships are involved in a dangerous situation.

In conclusion, it is my opinion that there is more need for good use of the existing tools (good sense, Rules of the Road, radar plotting and politeness) than for new tools, and at present the best course of action to be taken is that of trying to improve the preparation of the personnel responsible for the conduct of ships at sea, giving much greater importance to the problem of collision and including in their programme the mathematical investigation of this problem which would find its proper place there.

\section{Dr. H. C. Freiesleben (German Hydrographic Institute) writes:}

When after World War II radar was introduced for the avoidance of collisions, papers were published in nautical journals concerning the geometry of the problem. It has not been until the last two years that writers have attempted to give a complete and basic mathematical solution of the problem. In this Journal those were especially Calvert, 1,2 Garcia $^{3}$ and Hollingdale, ${ }^{4}$ whose contributions are deserving of thanks, particularly since they give all points of view possible.

For the avoidance of collisions by aid of radar it is necessary to consider absolute and relative motions. It is difficult even for a mathematically trained person to imagine relative and absolute motion in an intuitive manner. That is 
why the detailed discussion by these authors is so very useful. The basic principles, which, for instance, are in the case of Garcia the avoidance of certain sectors, in the case of Hollingdale and Calvert the changing of direction of sight-line in an anti-clockwise manner, are easily understood and valid for simple rules for memory.

All mathematical deliberations, however, depend on certain suppositions. To suppose and to conclude is the essence of all mathematical and logical procedures. Here lies the difficulty about which it is possible to gain clarity sine ira et studio and to come to an agreement. It is possible to solve completely the problem of collision avoidance by mathematical means. The navigator must understand that and be grateful to the mathematician who not only shows the basic possibilities but also gives rules intelligible for nautical practice indicating how to proceed in individual cases. On the other hand, the mathematician-and the navigator who gives mathematical rules is also a mathematician in the sense meant-must understand that the practitioner will always have scruples in accepting for all events the suppositions which the mathematician has to make.

Like any other codified regulation the Collision Regulations have to find the middle course between the logic of thinking for the general case and the illogic of happenings in the individual case. This is not an easy task. As Captain Wylie points out, there is no possibility of comprising by a few assumptions all cases that might occur. For action in congested waters with much traffic there must be different Rules to the case of a simple encounter between two ships in mid-ocean. (The existing Rules of the Road completed by Rule 29-precaution which may be required by the ordinary practice of seamen, or by the special circumstances of the case-the clear Rules 17-24 for keeping out of the way two ships in sight of one another.) It even seems to be wise to oblige only one ship to manœuvre, because the danger of faulty action is halved. Wylie is right in saying that these are philosophical ideas and not mathematical ones. One ought to add psychological ones as well. Nowadays there are numerous investigations being made on what a radar observer is able to detect and to conclude from the targets shown on a screen.

The whole matter is complicated by technical and organizational considerations. The technical development, for instance that of true-motion radar or the use of storage tubes will provide more and other features than those proposed by Calvert. We are much indebted to him for joining mathematical theory with the design of an instrument, but there is the danger that a new technique will outrun all such work.

The Rules of the Road are only effective if they are recognized by all ships and if they take into consideration the conditions which can be realized everywhere. Experience has taught us that one will come to an agreement only very slowly. Therefore, it is reasonable that the delegates of the governments proceed carefully in solving the problem of collision avoidance by radar. Radical proposals have, as we know, not so much chance of being accepted as those which are presented cautiously and step by step. It thus seems best to continue and extend the discussion of mathematical solutions in journals and at conferences in order to inform all people interested in navigation of what is possible.

\section{GENERAL REFERENCES}

1 Calvert, E. S. (1960). Manœuvres to ensure the avoidance of collision. This Journal, I 3, 127. 
2 Calvert, E. S. (1961). A comparison of two systems for avoiding collision. This Journal, 14, 379.

3 Garcia-Frias, J. (1960). Anti-collision radar sectors. This Journal, 1 3, 316.

4 Hollingdale, S. H. (196r). The mathematics of collision avoidance in two dimensions. This Journal, I 4, 243.

5 Morrel, J. S. (1961). The physics of collision at sea. This Journal, 14, 163.

6 Sadler, D. H. (1957). The mathematics of collision avoidance at sea. This Journal, 1o, 306.

\section{Collision Avoidance in the Air}

$$
\text { from E. P. Fairbairn }
$$

IN June $195^{8}$ the writer submitted to the Ministry of Aviation a paper, summarized below, on the avoidance of collisions in the air. The views expressed are his own and not necessarily those of the Company for which he works.

I. The rules of the air should recognize that the information available to the pilot, whether obtained by visual or 'electronic' means, is likely to be limited by the following:

(a) the pilot's 'field of view' is at most $\pm 90^{\circ}$ in azimuth and some $\pm 20^{\circ}$ in elevation relative to his aircraft heading.

(b) a collision course can be recognized, but not the heading, course or speed of the other aircraft.

2. It was shown by the simple but somewhat laborious method of plotting a number of collision courses for various angles of approach and relative speeds, that an effective and practicable manœuvre for collision avoidance was, for an aircraft which had another in its field of view, to alter course to the right. If each aircraft can see the other, both alter course; if only one can see the other, e.g. if one is overtaking the other, only that one alters course. If the alteration of course is effective at a distance of 10 times the required miss distance, e.g. at 10 miles for a miss distance of $\mathrm{I}$ mile, a course alteration of $8^{\circ}$ is sufficient in all cases, but is more than is necessary in some. The miss distance is increased if the aircraft which has the other on its right reduces speed, e.g. by climbing, and the one which has the other on its left increases speed, e.g. by diving. Even for the fastest aircraft this small change of course can be made effective with reasonable acceleration in a distance which is short compared with those suggested above.

3. From these considerations the proposed rules are:

(a) If a pilot detects another in his field of view on a collision course he should alter his course $10^{\circ}$ to the right.

(b) If the other aircraft is on his right he may with advantage decrease speed by about 5 per cent usually by climbing; if it is on his left he may increase speed similarly usually by diving.

The much more thorough analysis made by Hollingdale in 'The mathematics of collision avoidance in two dimensions' (Journal, 1 4, 243) confirms the correctness of these principles.

It is considered essential to have simple and definite rules which the pilot can apply automatically in all cases, and therefore the course should never be altered to the left. If there is a doubt whether the aircraft can safely pass 'starboard-to- 